\title{
FUTURO, CIDADES E TERRITÓRIO
}

JORGE GASPAR ${ }^{1}$

Para se avaliar a esperança, há-se de medir o futuro

Padre António Vieira

\begin{abstract}
RESUMO - Neste texto procurámos reconstituir os conteúdos que nos pareceram mais relevantes de uma apresentação feita no âmbito das conferências do IGOT. A exposição viveu muito de um conjunto largo de imagens que não é possível, nem operativo, transpor para a versão escrita. Estruturámos a reflexão segundo quatro pontos, que se seguem a uma introdução em que afirmamos a "materialidade" do futuro, na qual podemos projetar as cidades, em coerência com o seu passado. A natureza da cidade tem um passado, um presente e um futuro. O primeiro ponto chama a atenção para a importância da ficção, nomeadamente a ficção científica para o ordenamento do território do futuro, dando-se particular relevância às orientações da ciberfiction. No segundo ponto "O futuro das cidades hoje", abordam-se alguns caminhos da procura da cidade do futuro na atualidade e em diferentes latitudes e contextos socioterritoriais. Em "Os futuros sonhados dos pobres, dos escorraçados" chama-se a atenção para os sonhos de futuro que os mais deserdados, que fogem do presente, transportam consigo e procuram implantar no território, sempre que têm essa possibilidade. São valorizados exemplos do Portugal meridional, percecionado ao longo de séculos como terra de promissão. Segue-se um apontamento sobre cidade e utopia, dueto inseparável desde os primórdios de qualquer civilização urbana e que permanece vivo nos nossos dias em variados contextos políticos, sociais e geográficos. É aberta uma menção particular ao urbanismo de génese ilegal que ocorreu na Europa do Sul na segunda metade do século XX. Releva-se ainda a importância da revolução das novas tecnologias da informação, não só na construção da cidade do futuro, como no renascer de utopias. A concluir chamamos a atenção para a permanência do papel determinante da urbanização e das cidades na resolução de um grande número de problemas com que a Humanidade e cada indi-
\end{abstract}

1 Professor Emérito da Universidade de Lisboa, IGOT e Investigador Efetivo do CEG. E-mail: jorgegaspar@campus.ul.pt 
víduo se vão confrontando: "O ar da cidade torna o homem livre". Um planeta de cidades pode ajudar os humanos na senda da prosperidade e da felicidade.

Palavras-chave: Cidade; futuro; cyberpunk; cyberfiction; utopia.

ABSTRACT - FUtURE CITIES AND TERritory. In this text we seek to reconstitute the most relevant material from a presentation given at an IGOT conference. The exposition was comprised of a wide range of images, which is not possible to transpose into writing. The reflection presented in this paper is structured in four points, following the introduction which affirms the "materiality" of the future, enabling us to project the city consistent with its past. The nature of the city has a past, a present and a future. The first point draws attention to the importance of fiction, namely science fiction for territorial planning of the future, attributing particular relevance to cyber fiction. The second point, "The future of today's cities", addresses several research paths of which departing from the present identify the city of the future across different latitudes and socio-spatial contexts. In the "The future dreamt by the poor, expelled" attention is given to the dreams of the future that the most disinherited, fleeing the present, carry with them and seek to territorially deploy, whenever they have the possibility. Examples are presented of Southern Portugal, perceived for centuries as the promised land. Following this, a note is made on the city and utopia, an inseparable duet since the beginning of any urban civilization, which continues to remain alive in our time in diverse political, social and geographical contexts. This leads to a particular mention of the illegal origins of urbanization that occurred in Southern Europe in the second half of the twentieth century. It further reveals the importance of the digital revolution, not only in building the city of the future, but for the rebirth of utopias. To conclude, we draw attention to the permanence of the key role of urbanization and cities in solving a number of problems that will be confronted by humanity and each individual: "The city air makes men free." A planet of cities can help humans in the path toward prosperity and happiness.

Keywords: City; future; cyberpunk; cyberfiction; utopia.

RESUME - LE FUTUR, LES VILLES ET LE TERRITOIRE. On résume ici les aspects qui semblent les plus importants, parmi ceux qu’ont été présentés lors d'une conférence de l'IGOT. Celle-ci fut illustrée par de nombreuses images qu'il est impossible et non souhaitable de reproduire en version écrite. Notre réflexion a été construite en quatre points, succédant à une introduction affirmant la matérialité du futur que son passé projette sur la ville - toute ville ayant un passé, un présent et un futur. Le premier point rappelle l'importance de la fiction et surtout de la fiction scientifique ou de la cyber-fiction pour l'organisation future du territoire. Dans le deuxième point, "Le futur actuel des villes ", on indique quelques voies de conception du futur urbain à partir des faits actuels - à différentes latitudes et en divers contextes socio-territoriaux. Dans « les futurs désirés par les pauvres et les abandonnés ", on signale les rêves de futur que les plus déshérités, fuyant le présent, cherchent à implanter dès qu'ils le peuvent. Sont mis en valeur des exemples du Portugal méridional, qui a été ressenti au long des siècles comme une terre de promission. Vient ensuite une note sur la ville et l'utopie, un couple inséparable dès l'apparition de toute civilisation urbaine et qui demeure vivant de nos jours en divers contextes politiques, sociaux et géographiques. Mention particulière est faite à l'urbanisme de genèse illégale, présent dans le Sud de l'Europe dans la seconde moitié du XXème siècle. On fait aussi remarquer l'importance de 
la révolution des nouvelles technologies informatiques, non seulement pour la construction de la ville du futur mais aussi pour la renaissance des utopies. En conclusion, on note le rôle déterminant qu'ont l'urbanisation et les villes, dans la résolution d'un grand nombre des problèmes avec lesquels tant l'Humanité que chacun des humains sont confrontés. «L'air de la ville libère ses habitants ». Une planète urbanisée pourrait bien mener les hommes sur la voie de la prospérité et du bonheur.

Mots clés: Ville; futur; cyberpunk; cyber-fiction; utopie.

DEDICATÓRIA

Pensar o futuro entre os geógrafos, no Portugal de hoje, leva-nos seriamente ao encontro com os ensinamentos de Chris Jensen-Butler, cujo método rigoroso e honestidade intelectual nos faz muita falta. Sucessivas gerações de geógrafos e planeadores puderam beneficiar do enriquecimento teórico e da prática de construção e operação com modelos que nos ofereciam janelas para espreitar os possíveis futuros, que nos instigavam a refletir e a fazer escolhas. Nas nossas cooperações, em que eram indispensáveis o desenho e a operacionalização de modelos determinísticos e probabilísticos, lembro a forma como o Chris contribuía para a conceção, animação e implementação das várias fases de trabalho de grupo. De entre muitos estudos, planos e viagens de estudo, quero agora destacar a participação no Programa Portugal os Próximos 20 anos, promovido pela Fundação Calouste Gulbenkian, em que as metodologias utilizadas permitiram atingir resultados cuja melhor avaliação resulta do confronto com o que aconteceu no País 20 anos depois (1984-2003).

Aproveito a oportunidade para saudar os restantes colaboradores na componente geográfica do projeto: Diogo Abreu, Fernando Correia, João Ferrão e Ana Marin.

\section{INTRODUÇÃO}

O Futuro existe, não é uma abstração, tem materialidade, tempo e espaço, por isso, ao longo de milénios, tem sido visto como a Terra Prometida. Para Fred Polack o Futuro pode ser visto como um trabalho de reconstrução, que tanto interage com o presente como com o passado (Polack, 1973).

Assim, quando observamos as nossas cidades, as atuais, estamos, simultaneamente, a reconstruir o seu passado e o seu futuro: é da forma, da atitude, da crítica que somos capazes de levar a cabo, que vai depender o seu futuro. Como notei várias vezes, analisando um grande número de cidades, elas só são elegíveis, inteligíveis, através de um exercício de reconstrução do seu tempo histórico, através dos seus espaços; da mesma forma, nos meus exercícios de planeamento do território, a visão para o futuro, desta ou daquela cidade, foi sempre construída a partir de uma projeção do passado e do presente nos ecrãs que o futuro proporcionava.

Tanto quanto podemos antever no tempo futuro, a tensão milenar entre o sedentarismo e o nomadismo vai manter-se, ou mesmo acentuar-se, embora sob novas formas, possibilitada pelo desenvolvimento tecnológico dos transportes e das comunicações que, a partir de finais do século XX, atingiram expressões nunca imaginadas. 
Emerge assim, na urbanidade em que vamos entrando, uma aparente contradição: o desenvolvimento simultâneo do sedentarismo e do nomadismo. Quando a Humanidade caminha para o sedentarismo total - não na ruralidade, mas na urbanidade - avança também com novas formas e novos valores do nomadismo. Isto é válido para todos os humanos, de qualquer estrato social, que cada vez empreendem deslocações mais amplas para poder transacionar a sua força de trabalho, os seus saberes técnicos, a sua inteligência. Mas também é verdade que os novos nomadismos continuam a afetar mais os homens que as mulheres, o nomadismo pós-moderno não eliminou uma diferença milenar dos dois géneros - à movimentação do homem opõe-se a fixação e a centralidade da mulher: caçadores e camponeses versus emigrantes e estantes. Hoje em dia são os homens que dominam, por exemplo, nos bandos de profissionais e executivos que de manhã cedo enchem as gares dos aeroportos e dos comboios de alta velocidade.

\section{PASSADO, PRESENTE E FUTURO - DAS FICÇÕES ÀS PRÁTICAS DA GEO- GRAFIA E DO ORDENAMENTO DO TERRITÓRIO}

Voltamos aqui à questão da partição académica do tempo e do espaço pelas disciplinas irmãs que são a História e a Geografia (Gaspar, 2013). Não só ambas necessitam destes dois conceitos, como os operam através dos instrumentos comuns que são os mapas, adequados aos respetivos encaminhamentos analíticos: mapas do espaço e mapas do tempo que vários autores têm procurado integrar, desde as abordagens inovadoras e pioneiras de Torsten Hägerstrand e da sua escola (Hägerstrand, 1967, 1975; Carlstein, 1982). Um dos princípios-chave da Geografia Humana, a Natureza Focal da Atividade Humana (Philbrick, 1957), tanto se manifesta para o espaço como para o tempo, pelo que poderá ser útil e instrumental a cartografia do passado ou do futuro, como dos espaços (local, regional, global) através de mapas de projeção zenital, em que os polos são simultaneamente $\mathrm{o}$ agora e o aqui.

Assim deve ser também para o planeamento e ordenamento do território, tanto no plano teórico como no analítico e no prospetivo. Claro que outra questão é a da dimensão propositiva, em que os objetivos comandam o processo de abordagem. Nestes casos a cartografia deverá começar por privilegiar a isocronia, a isometria e o isotropismo.

Ora todos estes tipos de mapas são indispensáveis, quer para indagar o futuro como para fazer escolhas sobre os futuros desejáveis. Carecemos de Atlas sobre o futuro, nomeadamente, os dedicados às cidades e ao urbanismo. Como noutros âmbitos geográficos, a informação a utilizar existe em múltiplos domínios temáticos e diversos suportes informativos, da recolha no terreno ao ciberespaço, na literatura, nas investigações tecnológicas e sociais, nas artes e nas ciências.

Com maior incidência nas últimas décadas, as ciências sociais, aí incluindo a Geografia Humana, têm procurado nos processos de desenvolvimento das novas tecnologias de informação e comunicação, pistas para a prospetiva das cidades e dos territórios. São já várias as orientações e os progressos verificados na leitura do ciberespaço, dos seus 
dinamismos físicos e culturais. Mais cautelosas têm sido na utilização dos progressos verificados noutros domínios determinantes para os novos comportamentos dos indivíduos e da sociedade, mormente os que possibilitam alterações-recuperações na composição fisiológica do corpo humano, existindo já, no entanto, um número razoável de pesquisas, mais e menos especulativas, que nos levam a crer que em breve teremos, também na Geografia, uma síntese com os mínimos de base científica o que até há pouco tempo era quase exclusivo da ficção científica ${ }^{i}$. No entanto, nestes domínios, as propostas mais fascinantes de viagem ao futuro continuam a ser, como nos séculos transatos, proporcionadas pela ficção e, decisivamente, pela Ficção Científica, que, no que respeita a construção de novas realidades territoriais, tem no Do Androids Dream of Electric Sheep de Phillip K. Dick (1968) o início da mudança, cuja "visibilidade" foi proporcionada, enfim, pelo Blade Runner, o filme de Ridley Scott (1982). A partir daqui os conhecimentos da cibernética vão potenciar a SF (Science Fiction), nas suas variantes cyberpunk e cyberfiction, em que por via da compressão tempo-espaço e do papel determinante das cidades, na atualidade e projetado nos futuros (Kitchin \& Kneale, 2001; Abbot, 2007; Collie, 2011; Kukka et al., 2014).

Desde que há registos (escritos, sonoros, fílmicos) da ficção, vamos encontrando sugestões de futuros, desde a Bíblia às mais recentes aventuras no ciberespaço. E a cidade é, desde os tempos bíblicos, ator e arena centrais.

Assim, como em Thomas Morus, Júlio Verne, Emílio Salgari, Philip K. Dick, nós conseguimos espreitar propostas de futuro, também nos autores atuais, como William Gibson e companhia, por muito que nos custe, vemos que uma parte das distopias ficcionadas serão acomodadas nas cidades do futuro - mas sem as destruir, gerando novos espaços, novas organizações societais, novas urbanidades (fig. 1).

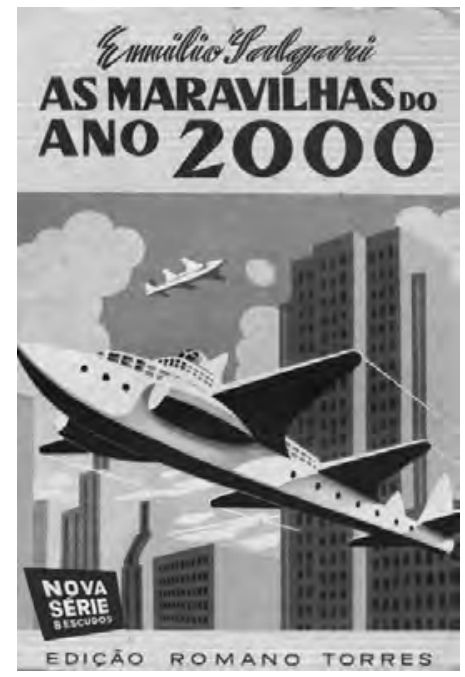

Fig. 1 - As maravilhas do ano 2000, de Emilio Salgari.

Fig. 1 - The wonders of the year 2000, from Emilio Salgari. 
O aprofundamento da cibercultura potencializa a capacidade de maior participação na gestão das cidades, bem como, já hoje se nota, uma maior preocupação com o espaço público, não só no que respeita à sua apropriação e manutenção, como à diversificação e intensificação dos seus usos. Por outro lado, a cibercultura, ao promover a competição entre espaços públicos e entre cidades, poderá, decerto, propiciar obsolescências mais rápidas, ciclos de vida mais curtos. Muitos sítios que hoje estão na moda e incitam à sua visitação e utilização poderão em breve ficar perdidos na dispersão do lixo que se acumula no ciberespaço, em localizações múltiplas, com diversificadas funcionalidades, mas não deixando de, no tempo, contribuir para a entropia final.

A leitura e análise crítica dos escritos da cyberfiction ou da cyberpunk podem trazer à Geografia e ao Urbanismo elementos e sugestões que proporcionam pistas ou até chaves para desvendar futuros. Também podem contribuir, e têm contribuído, como a ficção científica, num passado recente, para dar forma e inspiração às geografias imaginárias. Segundo Kitchin e Kneale (2001: 23) a cyberfiction é, de muitas formas, tremendamente produtiva, quer em termos de moldar o desenvolvimento tecnológico, quer de articular novos espaços emergentes, como a Internet. "Além disso estas ficções são ferramentas analíticas úteis na medida em que contêm um espelho das atuais espacialidades pós-modernas e revelam as possibilidades futuras..." (id., 24).

A cyberfiction, embora abranja muitas narrativas geográficas, foca-se prioritariamente nos futuros urbanos (id. Ib., 24). Vários autores já vêm sublinhando, desde os anos 90, que a ciberpunk e a cyberfiction proporcionam um mapeamento do urbanismo do futuro (Burrows, 1997, citado por Kitchin \& Kneale, 2001): "Os temas e processos que uma leitura sintomática da ciberpunk revela são bem mais perspicazes do que as que atualmente são tratadas nos trabalhos teóricos e empíricos da mainstream... Eu penso que obtemos um mais claro entendimento analítico dos processos urbanos contemporâneos na leitura de Gibson ou Stephenson do que quando lemos Sassen ou Castells..."(Burrows, 1997: 38).

A cyberfiction vale tanto pela sua criação imagética, acompanhada por uma continuada reflexão sobre a vinculação dos humanos às descobertas e experimentações tecnológicas, como pela capacidade de transporte para as futuras paisagens sociais. Neste último âmbito verifica-se uma aposta em "cenários" tendenciais, se bem que bem escorados em análises cientificamente sustentadas, macro e micro: o incremento das polarizações sociais, o aniquilamento da classe média e, de uma maneira geral, o aprofundamento da globalização e dos seus efeitos anómicos, em que se incluem as múltiplas fracturações, fragmentações e apropriações dos territórios.

Quando dizemos "vale tanto" não significa que têm mais ou menos valor operativo enquanto contributos para a construção de futuros. As dimensões económica e social, projetando corretamente tendências analiticamente definidas, podem contribuir para importantes avisos corretores de opções e trajetórias, em oposição a algumas ficções utópicas dos dois últimos séculos, que podem ter feito esquecer o continuado aprofundamento de um certo número de disfunções, como as que relevam o posicionamento ecológico da Humanidade. 
Se, por um lado, as cidades têm potencial para beneficiar da superação do espaço pelo tempo, por outro lado, o abrandamento da centralização no espaço urbano favorece o sprawl, a urbanização difusa, a perda de centralidade das antigas cidades que, na melhor das hipóteses, evolucionam para parques temáticos. Ora isto é tratado, desde os anos 1980, no cyberpunk e na SF (Kitchin \& Kneale, 2001: 26).

No que respeita à forma urbana e à sua relação com a estrutura socioeconómica, embora não exista uma total concordância na produção dos vários autores e diversas abordagens, parece clara a tendência para uma projeção no tempo futuro do que é observável nos nossos dias. Talvez possamos sugerir que a evolução da sociedade e do território nas últimas décadas já começou a desenhar as paisagens urbanas do futuro. William Gibson é, sem dúvida, o grande visionário da urbanização no futuro em diferentes continentes, em diferentes contextos culturais, sociais e económicos, conseguindo dar um vasto panorama do rasoiramento do planeta e ao mesmo tempo evidenciando situações únicas, quer ao nível da "grande" paisagem quer ao nível do local mais "local", desenhando os territórios que autores "cientistas", como William W. Mitchel, tinham já tipificado (Mitchel, 1999) (fig. 2).

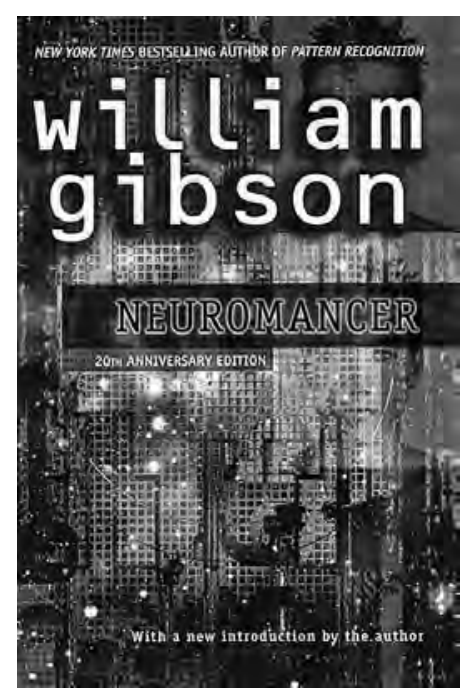

Fig. 2 - Neuromancer, de William Gibson.

Fig. 2 - Neuromancer, from William Gibson.

Há assim uma convergência entre os achados analíticos e a construção ficcionada, o que indicia que não estamos muito distantes, no tempo e no espaço, da coisa e do momento, em que estes fenómenos se vão declarar.

Outro aspeto "realista" e interessante é a capacidade de reciclagem que os "novos" humanos, desclassificados, marginalizados, evidenciam face a territórios abandonados, utilizados como lixeiras, onde se pode encontrar tudo o que já não é necessário aos gru- 
pos dominantes. Como assinalam Kitchin e Kneale (2001, 30), esses espaços oferecem "novos espaços públicos, sítios de resistência, e espaços de esperança, nos quais podem desenvolver-se as novas comunidades urbanas". Imaginemos os heréticos expulsos das suas comunidades, nas guerras religiosas que desde a Idade Média avassalaram a Europa; ou os gafos expulsos para as miasmáticas areias do litoral do centro de Portugal, ainda no século XVIII...; ou os excedentes humanos da Revolução Industrial europeia em busca das suas terras prometidas nas Américas, na Austrália ou noutras paragens.

Como alguns artistas plásticos, Gibson recorre, literariamente, à técnica da colagem, assumida por outros mestres do visionário, como Walter Benjamin, transportando do tempo atual para o tempo futuro estruturas, fragmentos de espaços, territórios, sejam oriundos das marginalidades de Tóquio ou de Hong Kong ou das favelas latino-americanas. As permanências/continuidades ocorrem em múltiplas situações "- O que tu queres é um paraíso - comentou o Linha Recta, depois de ouvir a exposição da situação do Case. - Investiga Copenhaga nas margens da zona universitária." (Gibson, 1984).

Quantas vezes, viajando noutra cidade, fora de horas ou fora dos lugares que nos são mais afins, temos tendência para a reverie cyberpunk/cyberfiction, o que tanto pode gerar o pânico ou o enjoo, o tédio também, como alguma euforia em que articulamos territórios (urbanos ou semiurbanos) utópicos com paisagens distópicas. O mesmo se pode passar com algumas leituras de ficções de fronteira, de hibridização, como por exemplo o que nos oferece a trilogia Milénio de Stieg Larsson (2005-2007). Ou, podemos ainda sugerir que esta, localizada entre guerras, nos prepara para a viagem à Sprawl Trilogy, do pós-3a Guerra Mundial.

\section{O FUTURO DAS CIDADES HOJE}

$\mathrm{Na}$ atualidade encontramos muitas equipas, em geral pluridisciplinares, a estudar o fenómeno urbano nos futuros, quer recorrendo a cenários mais ou menos complexos quer orientando-se segundo determinados vetores de mudança - tecnologias da informação e comunicação, alterações climáticas, evolução demográfica, sustentabilidades, finitude dos recursos, mobilidade, etc. Para uma boa síntese do estado da arte e discussão epistemológica da questão urbana veja-se o recente ensaio de Neil Brenner e Christian Schmid (Brenner \& Schmid, 2015).

Um exemplo muito interessante de investigação acontece no MIT com o SENSEAable City Laboratory, que, sob a direção de Carlo Ratti, vem explorando, em diferentes ambientes geográficos, as mudanças profundas que algumas cidades têm vindo a operar e a partir daí antecipar as soluções mais adequadas para o futuro. Respostas que, frequentemente, tratam questões muito concretas que se levantam do âmbito económico, social, cultural ou infraestrutural.

Outro exemplo interessante é o Future Cities Project, da União Europeia, muito focado nas adaptações necessárias às alterações climáticas, projeto a que se associou a cidade do Porto. 
Por seu lado, a cidade de Lisboa associou-se a um projeto com algumas semelhanças, o Connected Sustainable Cities, coordenado por William J. Mitchel e Federico Casalegno, e que além da Cisco Systems, teve como parceiros as cidades de Lisboa, Amsterdão, São Francisco, Birmingham, Seoul, Hamburgo e Madrid. Com intensivo recurso às TICs, tinha como principais objetivos uma gestão inteligente de recursos escassos como a energia e a água, uma maior eficácia na redução de efluentes gasosos, como as emissões de carbono, e um eficiente tratamento de lixos.

De largo espectro temático e grande alcance geográfico e temporal, é o projeto lançado pelo Reino Unido sobre os desafios que as suas cidades vão enfrentar ao longo dos próximos 50 anos. Os resultados já conseguidos e publicados impressionam pela vastidão e qualidade, organizados segundo seis temas principais: a vida das cidades, as economias urbanas, o metabolismo urbano, a forma urbana, a infraestrutura urbana e a governação urbana. Dos trabalhos já publicados, um dos mais estimulantes surgiu em 2014: A visual history of the future, sob a direção de Alan Wilson, que evidencia o "poder e a importância das cidades imaginadas e das visões urbanas através da cultura popular...”.

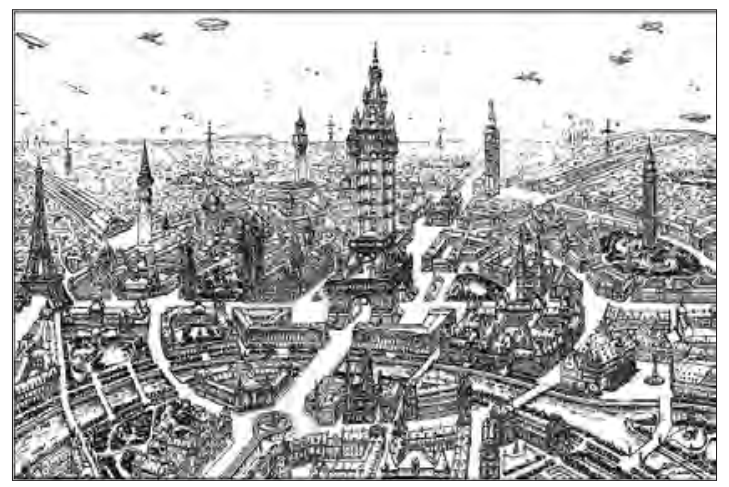

Fig. 3 - As cidades do futuro, de Eugène Hénard, publicado na American City em Janeiro de 1911.

Fig. 3 - The Cities of The Future from Eugène Hénard, published in American City, January 1911.

Outro exemplo de abordagem política e física do futuro da cidade foi demonstrado na iniciativa lançada em França pelo Presidente Sarkozi para a "descoberta" de grandes projetos com potencial para projetar o futuro da capital. Com o projeto Le Grand Paris, apresentado em 2007, Sarkozy pretendeu, numa certa tradição francesa, e como acontecera com os seus antecessores, Mitterrand e Pompidou ${ }^{\mathrm{ii}}$, que a sua presidência fosse marcada pela monumentalidade. Os resultados das várias propostas/ideias dos arquitetos e/ ou urbanistas iii convidados foram apresentados em 2009. Para lá da afirmação da grandeza de Paris, na França e no Mundo, estava presente a ambição de integrar, articular e promover a "co-habitação" entre a metrópole e o subúrbio, um problema patente na capital francesa, não só no plano urbanístico-patrimonial, mas também, e sobretudo, no social e cultural. 
Trata-se de uma abordagem clássica, confrontando a inventividade da mão dos artistas e a imaginação dos políticos, promovendo não só respostas para os grandes problemas, como também os efeitos do espetáculo que não deixam de fazer parte da natureza da metrópole. Afinal Sarkozy acabou por não ter o seu Grand-Chantier, e mesmo as polémicas do Grand Paris acabaram por não deixar uma memória assinalável, tão só momentos de festa e de ambição, sem um consenso que permita garantir o futuro.

Será interessante comparar as imaginações projetadas para Lisboa e a sua Área Metropolitana nestes tempos da viragem do século. Observaram-se vários exercícios de estratégias, para a capital, para a Área Metropolita e para cada um dos municípios que formam a suburbia, a norte e a sul. Faltaram as visões visionárias, não obstante o bom sucesso da intervenção da EXPO 98/Parque das Nações; fracassaram algumas tentativas localizadas, como o projeto para a Margueira/Lisnave, de Graça Dias, ou os idealismos de uma cidade ecológica para os terrenos da Quimiparque.

Cremos que merecerão uma referência as propostas que consubstanciaram o Projecto VALIS, promovido pela Comissão Europeia por mandato do Parlamento Europeu, e que tivemos a grande satisfação de coordenar, com a ajuda do Arquiteto José Manuel Fernandes e os contributos de geógrafos e arquitetos, como António Marques Miguel, Hestnes Ferreira, Carrilho da Graça, Graça Dias, Manuel Lacerda, entre outros. Foram talvez propostas antes do tempo, mas que nalgumas situações têm vindo a ser recuperadas, o suficiente para nos deixar na ilusão que também ajudámos a fazer o futuro de Lisboa e mesmo a Lisboa do futuro.

Verificamos, pois, como ao longo dos tempos, em diversos contextos culturais, políticos, religiosos, os humanos procuram sempre iluminar o futuro, tivesse ele lugar na Terra ou no Céu. E iluminar parece-nos a palavra adequada, no pleno sentido do termo: dar luz. O futuro desejado para as cidades tem muita luz, mesmo quando as propostas são muito pragmáticas, "terra à terra". Vejamos o caso da cidade jardim, projetada pela famosa obra de Ebenezer Howard, Tomorrow, que parte de uma utopia de contraponto à lúgubre cidade industrial, escurecida não só pela negritude das formas como pelas abordagens das artes e das literaturas, para oferecer uma urbanidade colorida, plena de luz e ar fresco (Howard, 1898).

A chave do futuro das cidades, além de ficar marcada pelo ambiente mais ou menos luminoso, tem muitas vezes a ver com a reconquista da natureza, o retorno ao natural, que pode implicar também uma dimensão religiosa, de retorno às origens que, na nova civilização, estão tipificadas nos mitos bíblicos. Mas em alguns períodos históricos foi possível criar novos paradigmas de futuros, de utopias, que se difundiram pelos vários continentes, obedecendo não só a ideias de imagens - o traçado viário, os edifícios marcantes (templos, escolas, sede municipal, parlamento...), como a uma toponímia capaz de transportar a mensagem de esperança, de futuro. Nesta aceção a palavra-chave mais universal e perene é também a mais simples: novo/nova; o mundo está povoado e repovoado de cidades novas, em todas as línguas de civilizações urbanas, por vezes associadas à metrópole, à cidade-mãe.

Também Portugal tem uma história contínua de edificação de vilas novas e de cidades novas, que chegam mesmo a desmultiplicar-se no tempo e no espaço, como no caso 
de Mazagão, um dos melhores exemplos de cidade (nova) do renascimento português, que dará origem, nos séculos XVIII/XIX, a uma Vila Nova de Mazagão, no Brasil, e a uma El Jadida (a nova) na sua implantação original, na costa marroquina.

O Brasil faz parte dos Novos Mundos recentes ou ainda vivos, necessariamente terra de futuro, de promissão, de utopia, que continuaram a marcar não só o imaginário de muitos, como a realidade vivida por tantos outros. Tudo isto foi ficando registado, na toponímia, do Rio Grande do Sul à Amazónia, onde destaco um nome de lugar recorrente, já em si uma terra prometida de outra Terra Prometida: Nova Califórnia. Mas a busca do futuro não para, da continuada engenhosidade das favelas aos condomínios murados e fechados da nova burguesia (Caldeira, 2000), dos novos credos religiosos às religiões populares renovadas e renascidas. Um caso muito interessante, porque pleno de ensinamentos, é o da fundação da Cidade de Deus, não a de Santo Agostinho, mas um bairro para pobres erguido pelas autoridades do Rio de Janeiro, quando Carlos Lacerda era governador do Estado da Guanabara. Depois, como em casos semelhantes, o território que seria pretensamente de regeneração humana, involui para um espaço de medo e perdição. O lugar tornou-se mundialmente famoso a partir do premiado filme de Fernando Meirelles de 2002 (fig. 4): o conteúdo, as técnicas de narrativa e as imagens que a sublinham, colocam esta obra próxima de ficções visionárias de futuros, na linha da literatura ciberpunk a que nos referimos.

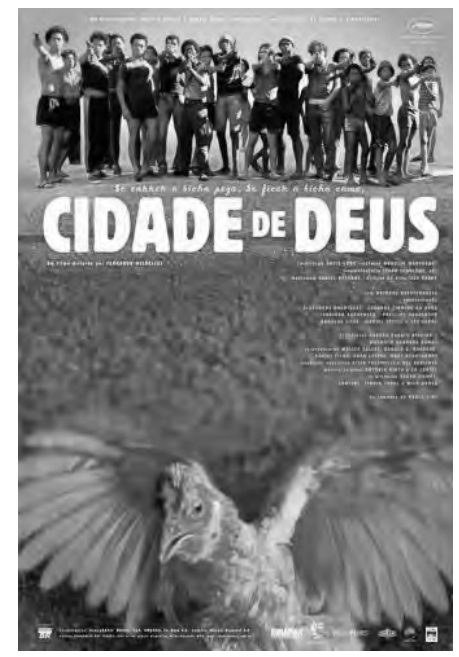

Fig. 4 - Cidade de Deus, 2002 (a partir do romance de Paulo Lins).

Fig. 4 - City of God, 2002 (from Paulo Lins' novel).

Mas noutras latitudes também as cidades se inventam, enquanto utopias, para alguns verdadeiras distopias, para outros a imagem do futuro, para outros ainda a sua negação, por ausência de sustentabilidade. Essas cidades em que muitos veem o futuro, começaram a manifestar-se ao longo do século XX na América do Norte e na Europa, e têm hoje uma dimensão de fantasia, por vezes onírica, que recorda o universo do mundo das cara- 
vanas, dos nómadas, que fizeram e desfizeram muitas cidades ao longo da História. $\mathrm{O}$ Dubai e outras cidades desse Oriente rico em trabalho e em petróleo, com um passado de histórias fantásticas, parecem querer marcar as imagens do futuro da cidade, viver uma fantasia, mais um sonho das mil e uma noites que, seguindo a antiga rota da seda, já se manifesta até à Mongólia interior e atinge Pequim, onde os novos Grandes Khans erguem novas cidades (do futuro?). Veremos.

\section{OS FUTUROS SONHADOS DOS POBRES, DOS ESCORRAÇADOS}

Todos os que partem na busca de qualquer coisa, de outro futuro, pretendem escapar de uma qualquer situação, de um futuro em linha com o passado. Como escreveu Yi-Fu-Tuan "Emigração assim como a transformação do ambiente in-situ são dois temas importantes - os dois temas mais importantes - da Geografia Humana. Ambos revelam um descontentamento com o status quo, um desejo de fugir (escape)" (Fu-Tuan, 1998: 8).

Pois o futuro existe a outras escalas e noutros ambientes: para os pobres que emigram, este é um ato de pensar o futuro, de o imaginar, de o querer. Nas terras arenosas do Baixo Sado, com o nível freático quase à superfície, como o atestam os topónimos "Mil Brejos" ou "Água Derramada", o povoamento permanente tardou a chegar, o paludismo não ajudava e a acessibilidade terrestre era fraca; pois com a valorização da cortiça e o excesso de gente no Norte e Centro do País, e também no Algarve, lá se aventuraram as famílias de camponeses pobres, "sem eira nem beira", na procura da "terra prometida". Só em pleno século XX chegou o comboio, Linha do Vale do Sado, para drenar os produtos da cortiça, alguma lenha e sobretudo os minérios das novas minas que por ali se foram escavando. É neste contexto físico e humano, a que se juntaram alguns catalães, mestres corticeiros, que seria construída a Aldeia do Futuro, que embora do lado "mau" da ferrovia, dificultando a expansão na direção da estrada e de Grândola, permitiu sonhar com um tempo melhor e que assim ficou inscrita na toponímia local: Rua da Esperança, Rua 25 de Abril, Rua $1^{\circ}$ de Maio, Rua Principal. Hoje as terras quase virgens que medeiam entre Grândola e as aldeias de outros foragidos que aqui procuram sobreviver, os "Negros do Sado", mostram alguma dispersão em foros, que foram breves sonhos de futuro e que parecem agora ter alguma perspetiva com a tímida aproximação do turismo, a mítica atividade do futuro ou com futuro: assim aparece o turismo em meio rural, um hotel para cães e... loteamentos clandestinos falhados...

Outro exemplo fascinante de terra onde têm aportado sucessivos sonhos de deserdados é o Porto Alto, aglomerado do concelho de Benavente que começou a crescer com a chegada, à margem direita do Tejo, da Ponte Marechal Carmona, em 1951. Então já aí tinham chegado os Avieiros que, além do Baixo Tejo, também povoaram o Baixo Sorraia e o Almansor, seu afluente, aí se iniciou também a estrada que levava até ao ferry boat que ligava a Lezíria Grande a Vila Franca de Xira. A ponte trouxe os camionistas e os primeiros negócios. Pouco a pouco, foi crescendo uma comunidade de muitas e variadas gentes, uma comunidade de fronteira. Curiosamente, um lugar/território, que já fora “Terra de Promis- 
são" no tempo dos muçulmanos, não tanto pela riqueza da terra, já referida pelos geógrafos antigos e também pelo septense Al Edrici, quando descreve a Balata, mas porque as autoridades islâmicas de Lisboa aí criaram um Alqueidão, uma propriedade coletiva dividida em lotes que anualmente sorteavam entre os pobres da cidade que a tanto tinham acesso. A mesma prática foi mantida no tempo dos nossos primeiros reis (Pradalier, 1975), sendo o Senado de Lisboa a entidade que distribuía os lotes pelos escudeiros mais necessitados.

Há meio século, quando o Norte procurou de novo o Sul, agora já não para as promitentes terras de pão do Alentejo, mas para o "milagre" das praias do Algarve, que iriam proporcionar a outros o sol e muito bons negócios, então o Porto Alto era ponto de passagem e de paragem de veraneantes, de empreiteiros, de trabalhadores e de mercadorias para a construção civil.

O nome escolhido para a principal tasca especializada no ensopado de enguias foi e é ainda uma expressão de génese nortenha - Vira Milho, que revela a alegria, a euforia, da grande azáfama: não havia tempo a perder, para construir novos futuros, tanto o do turístico Algarve como o das novas produções da Lezíria do Tejo, destinadas aos novos mercados da EFTA e que assim aparecia para os seareiros do tomate como um novo eldorado, por vezes como uma lotaria que até podia dar para o azar. Tudo isso confluía e estava em consonância com a ideia, com o ritmo e a musicalidade da expressão Vira Milho. Aqui acorriam camionistas, viajantes, turistas e homens de negócios que trouxeram mais comércio e indústria, em geral, de ciclos curtos. Homens e mulheres jovens ou quase maduros, que acompanhavam nas suas expectativas, mais ou menos indefinidas, gente de fronteira, em trânsito.

Em Portugal o Porto Alto foi uma das fronteiras do século XX, o cruzamento para diferentes futuros. E já na viragem para o século atual vieram outras oportunidades, outros viajantes do tempo: as indústrias de componentes para automóveis e os comerciantes chineses, com os negócios grossistas, o cash and carry das mercadorias mais variadas que chegavam em inumeráveis carregamentos de contentores. VIRA MILHO, a sensação manteve-se apesar de a casa das enguias fechar, por obsoleta.

Os negócios de mercadoria chinesa trouxeram novas mensagens de otimismo, de esperança, de felicidade, de futuro, bem explícitas nas designações de alguns armazéns. Num momento parecia que se consumavam os sonhos sonhados pelos sucessivos povoadores, gentes do Norte e do Centro que de há séculos vinham valar a lezíria do Tejo e de seus afluentes, construir a Ponte Marechal Carmona (1951) e sonhar ser agricultores, como seareiros nas campanhas do melão e do tomate.

Hoje o Porto Alto não deixa dúvidas a ninguém que configura uma paisagem urbana, que poderá bem transformar-se em cidade, de jure - há casos piores no Noroeste do País e noutras latitudes, incluindo na já referida Califórnia; é fácil estabelecer um paralelo com o sprawl de algumas seç̧ões da imensa polpa urbana que forma a grande Los Angeles... O que falta ou faltou a Porto Alto para aceder à carta de cidade? Primeiro, necessariamente, o que vai escasseando em todo o País: a gente, e depois a função administrativa e algum serviço de natureza pública, uma universidade ou politécnico, por exemplo... Tudo o resto viria por acréscimo. 


\section{CIDADE E UTOPIA}

Qualquer reflexão sobre a cidade no futuro dificilmente poderá evitar a introdução do tema, da ideia de Utopia. Um conceito e um vocábulo cunhado por Thomas Morus em 1516, eivado de valores do Humanismo. Então, a Utopia não estava no futuro, mas algures noutro ponto do Planeta, precisamente naquelas terras novas que os navegadores portugueses tinham vindo a descobrir, e cujos relatos já tinham referenciado, coisas extraordinárias em muitos domínios. A Utopia de Morus era um estado utópico, uma cidade no sentido grego clássico, que tinha várias cidades, semelhantes "tanto quanto a natureza do lugar o permitia" e o "protótipo" era a cidade de Amaurota, a capital, imaginada segundo os princípios e o desenho da cidade ideal do Renascimento, por sua vez inspirada na cidade grega, bem tipificada por Aristóteles.

A obra, publicada pela primeira vez em 1516, precede vários trabalhos que, segundo diferentes perspetivas, pretendiam antecipar novas formas de viver, dos valores ao habitat físico, de que destaco a Cidade do Sol, de Tommaso Campanella, obra publicada pela primeira vez em 1602. Um quarto de século depois, Francis Bacon publicava a sua novela incompleta, New Atlantis, uma utopia cristã numa ilha do Oceano Pacífico, o que sugeria a mundialização do Cristianismo, enraizado no Judaísmo (fig. 5). Deve notar-se que apesar da intensidade das relações económicas com o Oriente as viagens marítimas apontam para um futuro redentor a Oeste: fragmentos destas visões/imaginações viriam a ser experimentadas nas Américas, sobretudo nos Estados Unidos da América, a partir da segunda metade do século XVII.

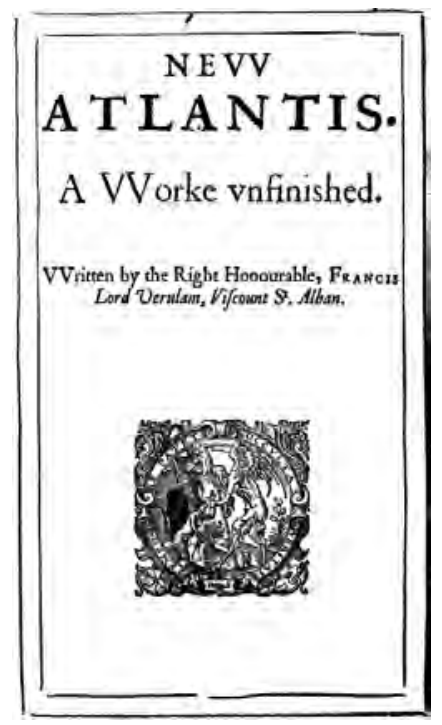

Fig. 5 - Nova Atlântida, de Francis Bacon (edição de 1628).

Fig. 5 - New Atlantis, from Francis Bacon (edition from 1628). Fonte: https://en.wikipedia.org/wiki/New_Atlantis 
Outra onda de pensamento utópico viria a ocorrer na sequência da Revolução Industrial, a partir do Reino Unido, mas estendendo-se a toda a Europa e à América, com duas linhas principais: o pensamento utópico de raiz socialista e a resposta paternalista de industriais preocupados com a questão social decorrente da distopia capitalista, por vezes associada a sociedades com ideários orientados pelo progresso económico e social, com distintas matrizes filosóficas.

A descoberta abre novas perspetivas não só ao conhecimento específico em que se dá a descoberta, mas também a outros domínios ou tão somente a outras imaginações. A descoberta é a demonstração renovada de que se pode ir mais além. Os períodos históricos em que se verificam descobertas de novos territórios, das viagens da Antiguidade às da Idade Moderna, até chegarmos às viagens no espaço extraterrestre, têm um efeito multiplicador na "descoberta" ou "construção" de novos territórios, utopias ou distopias. As viagens dos argonautas de Sindbad, a utopia de Morus, a Nova Atlântida de Francis Bacon, correspondem a etapas do conhecimento do território terrestre, como o são, relativamente às viagens no espaço interplanetário, as novas utopias e distopias descobertas pela ficção científica ou mais recentemente pela ciberficção.

Um facto que ocorre com frequência é a conexão entre esses futuros imaginados, futuros no sentido em que estão para lá do tempo em que ocorrem, e os passados em que se situam: o mais próximo em que se situa a descoberta ou o relato da mesma e o mais longínquo para onde é remetida a fundação (Bacon, 1626).

Outro aspeto a explorar mormente nas utopias "ocidentais" é a implícita inscrição numa fé messiânica que, direta ou indiretamente, remete para a Bíblia e contribui assim para a realização de viagens nas antiguidades que criaram as bases para um ecumenismo potencial, em que as "descobertas" de mundos utópicos mostram como foram guardados a fé e os valores que se julgavam perdidos...

$\mathrm{O}$ aproximar da viragem do século e a entrada no século $\mathrm{XX}$, ajuda à projeção de muitos futuros, para lá da grande onda festiva que atravessa os sistemas urbanos, nacionais e mundiais. A metrópole propõe e transporta o seu próprio futuro, exibindo as suas novidades, nas técnicas, na ciência, nas artes, nos novos estilos de vida. É já a cidade do luxo, do lazer e do espetáculo, conjugada com a aceleração dos movimentos e correlativamente com o aumento das desigualdades, das marginalidades, dos antagonismos sociais.

Aparecem novas/velhas utopias que configuram projetos de poder: a utopia para ricos e para pobres, dos industriais para os operários. Isto passa frequentemente pela "regeneração" da cidade industrial, no sentido de estabelecer a "metrópole do futuro". Constroem-se, assim, novos discursos políticos mas também novas cidades-ideais, no encontro das técnicas/das artes/das ciências e dos poderes políticos e até dos homens das letras, poetas, romancistas e cronistas, leitores e críticos das mudanças, dos desenhos que apontavam os futuros.

Entre nós temos alguns exemplos interessantes para estudar e compreender que leituras se faziam da cidade e que futuros se desenhavam. Claro que em boa medida estas ações não eram mais que os ecos das grandes metrópoles: Londres, Paris, Berlim, São 
Petersburgo, onde se podia ainda incluir Madrid, para referenciar o nosso maior poeta da cidade da $2^{\text {a }}$ metade do século XIX: Cesário Verde.

Mas a proposta mais interessante provem do encontro entre Fialho de Almeida, cronista do fenómeno urbano, com o arquiteto mais ativo e a la mode na viragem do século, Ventura Terra. As propostas para uma Lisboa Monumental (1906), de molde a que Lisboa não desmerecesse das metrópoles burguesas da Europa e de Paris, em particular, não deixava de construir também uma utopia para os pobres, para os trabalhadores - o Bairro Operário: uma visão paternalista, um ideal "rurbano", que permitia manter o "equilíbrio" social. A imagem e o traçado tinham inspirações na cidade-jardim, uma onda que percorria a Europa. Mas entre nós seria o "Estado Novo" de Salazar a "realizar" a "utopia", a dos Bairros Económicos, e o desenho que saiu dos estiradores dos arquitetos não andou muito longe da descrição de Fialho de Almeida.

Mas aquele ideal do bairro-jardim, com uma clara chamada para o mundo rural, era uma resposta insuficiente para as necessidades do grande número de rurais que afluíam às cidades e em particular à Grande Lisboa; por isso, as propostas do pós-guerra viriam a ter outra escala, outro desenho urbano, outra imagem, outro realismo, mas continuaram a ser insuficientes, crescendo paralelamente os bairros de lata. É neste contexto, face à incapacidade de resposta por parte do Estado e das Autarquias, que aparecem os loteamentos ilegais a partir dos anos 1950, de resto, à semelhança do que se passava nas principais cidades do sul da Europa, de Lisboa a Atenas (Gaspar, 1984). A possibilidade de autoconstruir uma casa própria num terreno adquirido por um preço acessível é o sonho de muitos dos carentes de habitação, não só em Lisboa como em várias cidades de pequena e média dimensão. Para um grande número desses novos urbanitas, os bairros clandestinos representavam uma utopia, pelo potencial evolutivo do lote, pelo papel de aforro que representava o acesso a casa própria individual. É assim que os loteamentos clandestinos irão constituir também uma oportunidade de valorização das poupanças, inclusive para muitos dos emigrados em países da Europa, mormente em França.

$\mathrm{O}$ acesso ao solo urbano, a uma casa própria, é um percurso para um futuro melhor, que chega a revestir uma visão messiânica do processo de "urbanização ilegal/clandestina”. Como relatei numa publicação de 1989, em 1975/1976, quando se levantaram dúvidas sobre a continuidade/validade dos loteamentos promovidos e vendidos por A. Xavier de Lima, um proprietário de um novo lote "numa frente do loteamento" disse-me com plena fé de que seria verdade "... e isto ainda poderia estar melhor, já deveríamos ter luz e água, se não tivessem corrido com o Xavier de Lima... que era homem para fazer tudo... mas ele está quase a voltar!” e logo a seguir,... “... várias pessoas já o têm visto passar por aqui perto, no seu Mercedes branco!" (Gaspar, 1989a). Atitudes semelhantes encontrei entre as populações de bairros de génese ilegal/espontânea, nos arredores de Madrid, de Barcelona, de Roma ou de Atenas (Gaspar, 1989b).

O bairro clandestino, com frequência, permite reconstituir a aldeia original, refazendo-se a comunidade e, ao mesmo tempo, permite manter ligações com a terra de origem. É assim que se estabelecem fluxos comerciais interessantes - o pão, o queijo, as batatas, a carne, que vêm da Terra; os grupos corais que os alentejanos vão criando de 
Vila Franca de Xira a Cascais, de Almada ao Montijo, e que, em comparação com os das aldeias originais, são igualmente genuínos com a vantagem de serem constituídos por gente mais jovem. É a utopia da continuidade: os da Corte do Pinto (Mértola) que vieram para o Prior Velho não só construíram, reconstituindo, as correntezas de casas, como "trouxeram" o barbeiro e o merceeiro. Curiosamente no fenómeno migratório tanto assistimos ao sonho do futuro em continuidade como ao do corte com o tempo (o passado) e o espaço (o país, a terra de origem). Escapar para uma Nova Califórnia deve implicar um corte com o ponto de partida e com o lugar que lhe está associado.

As próprias formas da urbanização do emigrante podem configurar sonhos, futuros independentes do passado. Ter a sua quintinha, com a sua casinha, uma família, uma piscina, dois automóveis +1 , uns animais: a utopia do sprawl, a urbanização difusa em contextos nacionais e sociais distintos pode manter a sua dimensão utópica e ao mesmo tempo uma projeção do futuro.

Uma questão que se pode colocar é a de saber se as novas formas de urbanização, que fogem à cidade, têm futuro, ou, por outras palavras, quanto tempo de vida têm as utopias do peri-urbano ou do anurbano, em que relevo as novas gerações dos megacondomínios fechados, da Celebration da Disney aos Alphaville que já marcam a hierarquia urbana no Brasil, como o fizeram (e fazem) os shopping centres.

Tomemos o título de uma obra fundamental para abordar esta questão Cidade de Muros - Crime, segregação e cidadania em São Paulo (Caldeira, 2000): além de analisar o fenómeno da segregação e fragmentação social e física da grande metrópole contemporânea, esta obra é decisiva para uma reflexão sobre os possíveis futuros da grande cidade, do Norte e do Sul, do Ocidente e do Oriente. A autora, logo na introdução, refere São Paulo, Los Angeles, Joanesburgo, Buenos Aires, Budapeste, Cidade do México e Miami (Caldeira, 2000, 3a edição 2011: 95) a que poderíamos acrescentar muitas outras, inclusive Lisboa.

Não só o aumento das desigualdades sociais, como outras formas conducentes à segregação social e territorial, como os movimentos migratórios, as diferenciações dos estilos de vida, as religiões e outras práticas sociais e culturais, bem como a pertença a grupos corporativos, são fatores de fragmentação, de demarcação de territórios, de edificação de fortalezas no interior das cidades do futuro.

Por tudo isto é necessário estar atento aos discursos diversos com que nos dias de hoje nos querem servir a cidade do futuro, configurando sucessivas campanhas de marketing, mais ou menos encadeadas e supostamente cimentadas pelas "novas" tecnologias ${ }^{\mathrm{iv}}$. O exemplo mais atual é o das divertidas smart cities, como se as cidades não tivessem sido sempre inteligentes. À semelhança da feira, o marketing para ser apelativo deve ser divertido, por isso, frequentemente, uma smart city é também uma fun city. Claro que o uso excessivo da expressão smart city banalizou ou desvalorizou o conceito, o que obriga a um aturado escrutínio da bibliografia que é assim referenciada. A propósito veja-se a excelente obra de Anthony M. Townsend, Smart Cities: big data, civic hackers, and the quest for a new utopia (Townsend, 2013).

As inovações tecnológicas, como em todas as épocas históricas, continuam a oferecer um potencial para melhorar as sustentabilidades das cidades e o bem-estar dos seus habi- 
tantes. Como noutros tempos históricos as inovações terão que ser bem geridas e bem aplicadas. Ora o potencial tecnológico dos dias de hoje nem sempre é aplicado com o maior rigor, como frequentemente nos damos conta ao verificar as opções de política para as infraestruturas, bem evidentes em vários exemplos no âmbito do saneamento básico, da produção e distribuição de energia, dos transportes públicos, entre outros.

Quando nos confrontamos com os dados observáveis no dia a dia das cidades verificamos como a deficiente aplicação do potencial tecnológico afeta primordialmente os mais frágeis, lugares ou cidadãos, pelo que é necessário orientar a reflexão para os conceitos dominantes e as formas de governo da cidade. É necessário recuperar e aprofundar a transparência da governação e a correlativa prestação pública e regular de contas, direcionada para a normal avaliação política. Assim, por exemplo, o egoverno não dispensa as tradicionais formas de governação democrática.

Um exemplo das modernas formas de governar a Polis, possibilitada pelas novas tecnologias da informação e comunicação, é-nos fornecido pelo "jogo" do orçamento participativo, que tanto poderemos considerar uma boa introdução à gestão participativa, como um enviesamento da mesma. De facto, esse "jogo" é muitas vezes um bom entretenimento, sem dúvida útil para atrair alguns segmentos da comunidade para os conteúdos e formas de gestão da coisa pública, mas ao mesmo tempo pode reduzir o âmbito do necessário escrutínio público do governo da cidade. É assim que amiúde encontramos referências à manutenção ou mesmo aumento da opacidade que caracteriza muitos atos do planeamento e da gestão das questões mais relevantes para o futuro das cidades.

\section{OUTRAS QUESTÕES}

"Mas será que as cidades nos fazem prósperos, inteligentes, saudáveis e felizes?" Esta foi uma questão que me foi oportunamente levantada por Mário Vale e que eu retomo agora a propósito do futuro das cidades ou das cidades no futuro.

Conhecemos relativamente bem a história da cidade e as histórias de um grande número de cidades, ao longo de alguns milhares de anos e, no essencial, nas suas dimensões geográficas, sociais, económicas e culturais não se registaram grandes alterações na essência, na natureza das cidades. Por isso temos uma razoável acumulação de conhecimento para responder àquela questão: sim. Também podemos arriscar com uma razoável probabilidade de acertar, que o futuro das cidades não vai ser muito diferente: os princípios de distribuição espacial, a organização interna, as formas de relacionamento social e económico da cidade dos futuros não serão basicamente outros dos que podemos rastrear ao longo daqueles dois a três mil anos para os quais temos informação credível sobre a vida das cidades.

Continuará a ser a cidade o lugar que oferece mais oportunidade de afirmação do indivíduo, pois é aí que ele pode aprender com outras experiências, onde consegue mais informação, tendo sempre em conta uma crescente valorização das técnicas de informação e comunicação. Por isso os urbanitas do futuro têm muitas probabilidades de ser mais 
e mais inteligentes e por isso mesmo também saberão cuidar melhor da sua saúde. Por último, face à grande questão que sempre se colocará aos humanos: "onde está a felicidade?”; se considerarmos o acesso às necessidades básicas - alimentação, habitação, saúde e educação, e a sua conjugação com o bem fundamental que é a liberdade, é sem dúvida na cidade que o acesso conjugado está mais garantido. Continua a ser válida a máxima medieval de que "o ar da cidade torna o homem livre".

A urbanização e a cidade constituem a chave para a sustentabilidade ambiental do Planeta, como o têm referenciado estudos recentes, mormente os que tratam das respostas para as alterações climáticas. Por outro lado, têm permitido a qualquer nível territorial, do local ao planetário, e apesar de todas as dificuldades e disfunções bem referenciadas, o encontro de respostas para as grandes questões sociais, económicas, políticas e culturais. Deve, todavia, notar-se que no bom governo da cidade, tal como nos foi demonstrado desde a Antiguidade, continuam válidos os princípios sistematizados por Aristóteles. Assim, por exemplo, a localização, o sítio e o bom desenho continuam a fornecer as respostas para nos prepararmos para as alterações climáticas.

Foi a urbanização e a constituição de redes de cidades, "as armaduras urbanas", que permitiram o progresso nas áreas mais fustigadas pelas fomes e pela falta de acesso aos cuidados de saúde, como é o caso de grande parte da África ao sul do Saara. O "Milagre Indiano" foi possível graças ao processo de urbanização, como o demonstrou de forma superlativa Gurcharan Das na sua obra fascinante India Unbound (2000). A produção de bens e serviços é necessária, mas não tem a eficácia necessária sem uma adequada distribuição, como se verifica ainda hoje no mundo subdesenvolvido, mas também de forma crescente em enclaves do Primeiro Mundo, como o tem demonstrado o alastramento de fenómenos dos "food deserts" (Del Casino Jr, 2015).

A urbanização total do Planeta, ou a tendência para essa meta, gera novas oportunidades para uma larguíssima maioria dos humanos, para quem a "fuga" dos campos foi muitas vezes a busca de um sonho, se quiserem, da cidadania, ainda que só muito poucos o viessem a sentir, a concretizar. Mas um planeta urbanizado, um planeta de cidades, não será nunca um planeta estático, pelo contrário, ao gerar mais informação também gera mais movimentos e são estes que permitem a busca da prosperidade, do conhecimento, do bem-estar, quem sabe se o vislumbre do que se poderá chamar felicidade.

\section{BIBLIOGRAFIA}

Abbott, C. (2007). Cyberpunk cities: science fiction meets urban theory. Urban studies and planning faculty publications and presentations. Paper 57. http://pdxscholar.library.pdx.edu/usp fac/57

Azevedo, A. F., Pimenta, J. R. \& Sarmento, J. (Eds.) (2009). Geografias do corpo - ensaios de Geografia Cultural. Porto: Livraria Figueirinhas.

Brenner, N. (Ed.) (2013). Implosions/explosions: towards a study of planetary urbanization. Berlin: Jovis.
Brenner, N. \& Schmid, C. (2015). Towards a new epistemology of the urban?. City, 19 (2-3), 151-182.

Burrows, R. (1997). Virtual culture, urban social polarisation and social science fiction. In B. Loader (Ed.) The governance of cyberspace (38-45). London: Routledge.

Caldeira, T. (2000). Cidade de muros crime, segregação e cidadania em São Paulo. (3ªedição, 2011), São Paulo: EDUSP. 
Carlstein, T. (1982). Time resources, society, and ecology: on the capacity for human interaction in space and time. London, Boston: Allen \& Unwin.

Collie, N. (2011). Cities of the imagination: science fiction, urban space, and community engagement in urban planning. Futures, 43, 424-431.

Das, G. (2000). India Unbound. New Delhi: Viking Penguin Books India.

Del Casino Jr, V. J. (2015). Social geography I: food. Progress in Human Geography, 39 (6), 800-808.

Dick, P. K. (1996[1968]). Do androids dream of electric sheep?. New York: Ballantine Books.

Doxiadis, C. \& Papaioanou, J. (1974). Ecumenopolis: the inevitable city of the future. New York: Norton.

Gaspar, J. (1984). Urbanization: Growth, Problems and Policies. In A. Williams (Ed.), Southern Europe Transformed (208-235). Londres: Harper \& Row.

Gaspar, J. (1989a). Do Sebastianismo na Urbanização Clandestina. In C. M. Rodrigues, et al. (Eds.), Clandestinos em Portugal - Leituras (124127). Lisboa: Livros Horizonte.

Gaspar, J. (1989b). Aspectos da Urbanização Ilegal nos Países Mediterrâneos da OCDE. In C. M. Rodrigues, I. Guerra, J. Cabral, J. Gaspar, J. M. Fernandes, N. R. Silva, N. Matias, Clandestinos em Portugal - Leituras (8291). Lisboa: Livros Horizonte.

Gaspar, J. (2013). Continuamos a procurar a Geografia: o que é e para que serve. Infogeo, 25: 19-29.

Gibson, W. (1984). Neuromancer. ACE books. Tradução portuguesa de Fernando Correia Marques, Gradiva, Lisboa 2004.

Gibson, W. (1984-1988) Sprawl Trilogy: Neuromancer (1984), Count Zero (1986), and Mona Lisa Overdrive (1988).

Howard, E. (1902). Garden Cities of To-morrow ( $2^{\text {nd }}$ ed.). London: Swan Sonnenschein \& Co.
Hägerstrand, T. (1967) (1953). Innovation diffusion as a spatial process [Innovationsförloppet ur korologisk synpunkt]. Postscript and translation by Allan Pred; Translated with the assistance of Greta Haag. Chicago: University of Chicago Press.

Hägerstrand, T. (1975). Space, time and human conditions. In K. Anders, L. Lars, S. Folke (Eds.), Dynamic allocation of urban space (3-14). Lexington, MA: Lexington Books.

Katsikis, N. (2014). On the Geographical Organization of World Urbanization. In MONU \#20: Geographical Urbanism, April 2014.

Kitchin, R. \& Kneale, J. (2001). Science fiction or future fact? Exploring imaginative geographies of the new millennium. Progress in Human Geography, 25 (1), 19-35.

Kukka, H.; Luusua, A.; Ylipulli, J.; Suopajärvi, T.; Kostakos, V. \& Ojala, T. (2014) From cyberpunk to calm urban computing: Exploring the role of technology in the future cityscape. Technological Forecasting \& Social Change, 84 (2014), 29-42.

Larsson, S. (2005-2007). Millennium-serien. Tradução portuguesa, Lisboa: Oceanos.

Mitchel, W. J. (1999). Urban Life, Jim - But Not As We Know It. Cambridge: The MIT Press.

Philbrick, A. K. (1957). Principles of areal functional organization in regional human geography. Economic Geography, 33, 299-336.

Polak, F. (1973). The image of the future. Translatée! and Abridged by Elise Boulding, New York: Elsevier.

Pradalié, G. (1975). Lisboa da Reconquista ao fim do século XIII. Lisboa: Palas editores.

Townsend, A. M. (2013). Smart cities: big data, civic hackers, and the quest for a new utopia. New York: W. W. Norton \& Company.

Tuan Y-F. (1998). Escapism. Baltimore: Johns Hopkins University Press.

i Sobre esta matéria veja-se o conjunto de ensaios editados por A. F. Azevedo, J. R. Pimenta e J. Sarmento, sob o título Geografias do Corpo - ensaios de Geografia Cultural, Porto, 2009.

ii Jacques Chirac optara por outros temas de afirmação: “Trois chantiers qui ne sont pas de Pierre" - a luta contra o cancro, a luta contra a violência rodoviária e a ajuda aos menos válidos.

iii Seis francesas, uma alemã, uma italiana, uma britânica e uma dos Países Baixos.

iv José Manuel Simões na conferência A cidade do Homem - Desafios do novo urbanismo, que proferiu em 5 de dezembro no auditório da CCDR de Lisboa, enumerou um amplo leque de adjetivos com que se tem procurado chamar a atenção para as "novas" cidades. 